\section{Rapid Field Assay for Pineapple Fruit Acidity}

\author{
Robert E. Paull ${ }^{1}$, Gail Uruu ${ }^{1}$, and Nancy Jung Chen ${ }^{1}$
}

AdDitional InDex words. Ananas comosus, clones, conductivity, digital acidity meter, titration, juice acidity

SUMMARY. The sugar-to-acid ratio of pineapple (Ananas comosus L.) contributes toward giving the fruit its unique flavor. This ratio is an important indicator of both commercial and organoleptic ripeness, and it is useful in determining a harvest date. Citric acid is the major acid in pineapple and usually is determined by titration to a specific $\mathrm{pH}$ endpoint, while sugars are determined as total soluble solids by refractometry. Both acid and sugar levels vary with the season in the year-round production cycle. Acid titration is slow and difficult to perform in the field. A digital acidity meter based upon diluted juice conductivity was evaluated for potential field use. The readings obtained from the meter varied with clone and fruit potassium concentration. The meter had utility for field use to evaluate fruit quality and harvest date. Because fruit potassium levels can vary between harvests, the meter should be recalibrated on a regular schedule to adjust for potential crop management and seasonal effects.

$\mathrm{T}$ The sugar-to-acid ratio of pineapple (Ananas comosus L.) contributes toward giving the fruit its flavor (Paull and Chen, 2003). This ratio is an important indicator of both commercial and organoleptic ripeness and is useful in determining a harvest date. Variation of fruit acidity and sweetness are associated with the clone used, fruit maturation, growing conditions, and season (Bartholomew and Paull, 1986; Bartolome et al., 1995; Dorey et al., 2016; Py et al., 1987; Saradhuldhat and Paull, 2007; Singleton and Gortner, 1965). Fruit acidity increases during fruit growth; and as the fruit approaches maturity and starts to ripen, the acidity declines (Saradhuldhat and

Received for publication 5 June 2020. Accepted for publication 22 July 2020.

Published online 2 September 2020

${ }^{1}$ Tropical Plant and Soil Sciences, University of Hawaii at Manoa, 3190 Maile Way, Honolulu, HI 96822

The project was supported in part by the National Institute of Food and Agriculture, U.S. Department of Agriculture, under an agreement 58-2040-5-010 through the Agriculture Research Service and Hatch Project H862 to Robert E. Paull.

We wish to thank Dole Food Company, Hawaii for supplying the fruit for this study.

R.E.P. was responsible for conceptualization, securing experimental fruit, assisting in data analysis and writing, editing, and submission. G.U. was involved in fruit collecting and sampling, taking readings and titrations, and data collecting and curation. N.J.C. assisted with sampling, data collecting, and reviewing manuscript.

R.E.P. is the corresponding author. E-mail: paull@ hawaii.edu.

This is an open access article distributed under the CC BY-NC-ND license (https://creativecommons.org/ licenses/by-nc-nd/4.0/).

https://doi.org/10.21273/HORTTECH04664-20
Paull, 2007). Citric acid shows the greatest changes during fruit growth, increasing and then reaching a peak before ripening, whereas malic acid shows little change during development (Chan et al., 1973; Saradhuldhat and Paull, 2007; Singleton and Gortner, 1965). The sugar-toacid ratio is recommended as a harvest index (Paull and Chen, 2003). However, citric acid alters sucrose perception (Schifferstein and Fritiers, 1990); pineapple clones may have sufficient sugars - but high citric acid may mask some of the sweetness perception.

Major changes occur in pineapple fruit acidity between the 'Smooth Cayenne' high-acid clone (PRI\#3621 ) and a low-acid clone (PRI\#63$555)$ and other low-acid hybrids. The high-acid clone gradually increased in fruit acidity from $1.4 \mathrm{meq} / 100 \mathrm{~mL} 6$ weeks from flowering, and peaked a week before harvest at $10 \mathrm{meq} /$ $100 \mathrm{~mL}$. In contrast, the low-acid clone increased in acidity 6 to 8 weeks after flowering, peaked 15 weeks after flowering at $9 \mathrm{meq} / 100 \mathrm{~mL}$, and then sharply declined in 2 weeks to $6 \mathrm{meq} / 100 \mathrm{~mL}$ (Saradhuldhat and Paull, 2007). The increase in total soluble solids (TSS) of the low-acid clone began 6 weeks after flowering,

\begin{tabular}{llll}
\hline $\begin{array}{l}\text { Units } \\
\begin{array}{l}\text { To convert U.S. to SI, } \\
\text { multiply by }\end{array}\end{array}$ & U.S. unit & SI unit & $\begin{array}{l}\text { To convert SI to U.S., } \\
\text { multiply by }\end{array}$ \\
\hline 29.5735 & $\mathrm{fl} \mathrm{oz}$ & $\mathrm{mL}$ & 0.0338 \\
0.1 & $\mathrm{ppm}$ & $\mathrm{mg} / 100 \mathrm{~mL}$ & 10 \\
0.001 & $\mathrm{ppm}$ & $\mathrm{mg} \cdot \mathrm{g}^{-1}$ & 1000 \\
1 & $\mathrm{ppm}$ & $\mu \mathrm{g} \cdot \mathrm{mL}^{-1}$ & 1
\end{tabular}

and for the high acid clone at 12 weeks after flowering. The increase in titratable fruit acidity (TA) paralleled the changes in the citric acid content of both clones. The malic acid concentration in both clones varied between 3 and $5 \mathrm{mg} \cdot \mathrm{g}^{-1}$ and showed no marked changes just before harvest. Titratable acidity is affected by rainfall, solar radiation, and temperature at different stages of fruit development, with rainfall and temperature explaining $60 \%$ of the variance (Dorey et al., 2016). The developmental changes in fruit potassium is also correlated with fruit acidity (Marchal et al., 1981; Soares et al., 2005; Spironello et al., 2004) in both the high- and low-acid clones (Saradhuldhat and Paull, 2007). Industry research (Tisseau and Tisseau, 1971) has shown that a potassium application at flowering can increase fruit acidity by $\approx 0.1 \%$.

The most common method to determine fruit acidity is titration using an alkali (sodium hydroxide, $\mathrm{NaOH}$ ) with a colored indicator or with a $\mathrm{pH}$ meter (potentiometric) to its half-equivalence point ( $\mathrm{pKa}$ ). One difficulty with the colored indicator is detecting subtle changes at the transition range. Titration also requires a large sample, is slow, and is not suited for wide field use. An alternative for field use is near-infrared spectroscopy that has the potential for TSS-but the results for acidity are inconsistent (Shiina et al., 1992; Subedi et al., 2012; Teerachaichayut and Ho, 2017). Also, the portable nearinfrared instruments are expensive. Atago Co. Ltd. (Tokyo, Japan) has developed a pocket instrument (a digital acidity meter) to measure acidity by conductivity and TSS by refractometry with the conductivity sensor printed on the refractive index glass window. The digital acidity meter requires no solutions except for dilution and comes in a number of versions for different fruit types \{citrus (Citrus spp.), grape (Vitis vinifera L.), tomato (Solanum lycopersicum 
L.), strawberry (Fragaria ×ananassa Duchesne), banana (Musa spp.), kiwifruit [Actinidia deliciosa (A.Chev.) C.F.Liang \& A.R.Ferguson], pineapple, apple (Malus domestica Borkh.), and blueberries (Vaccinium corymbosum L.)\}. TSS, acidity, and the ratio of sugars to acids are displayed. It is fast (3 s), requires only $0.2 \mathrm{~mL}$ of juice, and has a stated measurement accuracy for acidity of $\pm 0.1 \%$ from $0.1 \%$ to $1.0 \%$ with a relative precision of $\pm 10 \%$ (1.01\% to $3.5 \%)$. The instrument has an offset feature to adjust for discrepancies from titration values. The stated accuracy allows the instrument to have some research use and lends itself to rapid quality evaluation in commerce. The meter has been used for research on mandarin (Muharfiza et al., 2017), strawberry ( $\mathrm{Li}$ et al., 2018), peach (Huan et al., 2018), bayberry (Chen et al., 2019), and pitaya (Wu et al., 2020) following the manufacturer's instructions. A major criterion for pineapple harvest consideration is TSS with a State of Hawaii grade minimum of $12 \%$ with no acidity criterion, although a sugarto-acid ratio of 0.9 to 1.3 is recommended (Paull and Chen, 2003; Smith, 1988; Soler, 1992). If the fruit in the field is nearing the harvest stage and meets the minimum of $12 \%$ TSS, then this instrument could be used to estimate harvest date, taking into account the decline in fruit acidity after fruit maturity and the sugarto-acid ratio. Standardizing the sugar-to-acid ratio would allow more consistent fruit quality throughout the year.

Because pineapple flowering is scheduled by applications of ethephon, and as fruit are harvested from different fields on the same plantation year-round, we were interested in the potential seasonal effects on the instrument's accuracy and whether different clones showed different responses. Organic acids such as citric and malic acids are weak electrolytes, with monovalent cations such as potassium being the likely counter ion in plants. The conductivity of a dilute solution $(2 \%)$ of potassium chloride is about 5-fold greater than that of sodium citrate and 10-fold greater than citric acid (Apelblat and Barthel, 1991; Wolf, 1966). Small changes in cellular potassium could therefore have a greater effect on conductivity than changes in acid contents and could impact the acidity readings obtained with this meter. We evaluated the utility of this meter for field and packinghouse use to monitor fruit sugars and acids.

\section{Materials and methods}

The digital acidity meter (PALBX/Acid; Atago USA, Bellevue, WA) was evaluated using two pineapple cultivars developed by the Pineapple Research Institute (PRI), Honolulu, HI: PRI 73-50 (MDI) and PRI 73114 (MD2) (Taniguchi et al., 2008). These commercial cultivars are commonly known as Hawaiian Gold and MD-2, respectively. Fruit was harvested from a Dole Food Company (Honolulu, HI) fields in central Oahu and returned to the laboratory within 3 hours. Juice was extracted with a fruit or garlic press. Juice was diluted $0.1 \mathrm{~mL}$ to $10 \mathrm{~mL}$ with distilled water before readings were taken from each fruit with the digital acidity meter. The meter output was as $\mathrm{g}$ citric acid per $100 \mathrm{~mL}$. Fruit at harvest maturity ( $\mathrm{n}=10$ to 15 ) were collected directly from the field at different times throughout one year.

Titration was carried out with an automatic acid titrator (Model HI 84432; HANNA Instruments, Inc., Woonsocket, RI). Fruit potassium (K) was determined with an ion-selective electrode (Candy $\mathrm{K}+$ Meter; Spectrum Technologies, Inc., $\mathrm{Au}^{-}$ rora, IL), and potassium concentration was expressed as $\mathrm{mg} \cdot \mathrm{L}^{-1}$ relative to a potassium chloride (KCL) standard (Saradhuldhat and Paull, 2007). The meter was also evaluated using citric acid solutions with different potassium chloride concentrations. Data were analyzed with SAS Statistical Package (Version 9.4; SAS Institute, Cary, NC).

\section{Results and discussion}

The fresh pineapple fruit market is dominated by two clones that are products of the former Hawaii Pineapple Research Institute's breeding program: PRI 73-50 and PRI 74114 (Taniguchi et al., 2008). These clones respond differently in yield and fruit quality in various areas of the tropics, with PRI 73-50 being more suited to the cooler tropics. Both are low-acid clones when compared with the higher-acid clones used commonly in the canning industry and before the late 1990s as fresh fruit.
The clones also show a different relationship between acidity measured by titration and estimated by conductivity (Fig. 1). PRI 73-50 had a lower acid range than did PRI 73-114, with a lower slope $[\Upsilon=0.0424+1.72 \mathrm{Ti}$ tration (Fig. lA) vs. $\Upsilon=-0.32167+$ 2.45Titration (Fig. 1B)]. TSS was similar between the two varieties being generally in the range of $12 \%$ to $16 \%$ (TSS data not shown). The scatter in acidity around the regression line, though generally within the $95 \%$ confidence limit, suggests some degree of fruit-to-fruit variation and a potential for greater than $10 \%$ variation than results obtained from titration.

One potential source of variation considered was fruit potassium; however, the relationship between fruit potassium and acidity was low $\left(r^{2}=\right.$ $0.118 ; P=0.056$ ) (Fig. 2). The results showed considerable fruit potassium variation, from 16 to $27 \mathrm{ug} \cdot \mathrm{mL}^{-1}$; that finding could explain some of the variation in the digital acidity meter's readings (Fig. 1).

We evaluated the relationship between citric acid concentration and estimated acidity with the digital

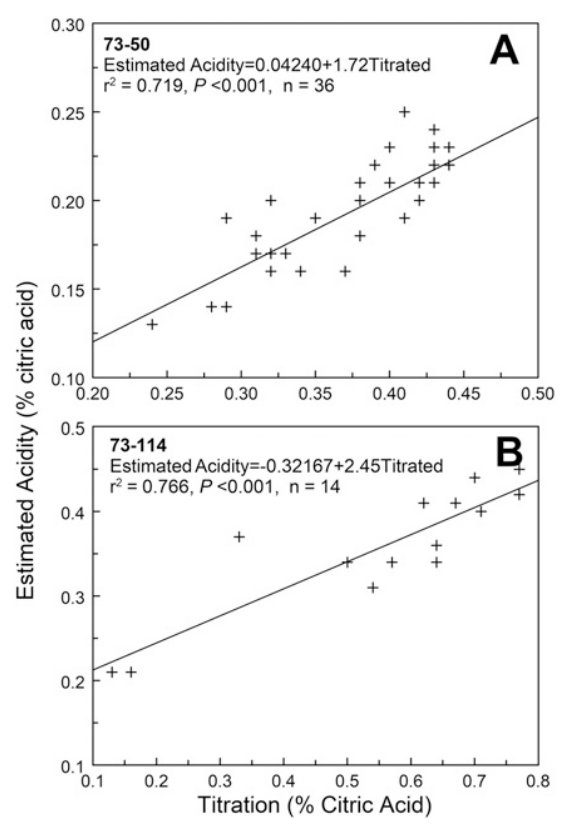

Fig. 1. Relationship between titratable acidity determined by titration and using the digital acidity meter for two cultivars of pineapple (A) PRI 73-50 (MDI) and (B) PRI 73-114 (MD2). The $x$-axis scale (\% citric acid) was different for each clone. 
acidity meter and found a linear regression with $r^{2}=0.948$ and $P<$ 0.0001 (Fig. 3A). The instrument was also evaluated regarding different levels of potassium and two levels of citric acid (Fig. 3B). The slope at the two different levels of citric acid were similar as the potassium level increased. This confirmed that different levels of potassium in the fruit could increase the digital acidity meter's acid readings.

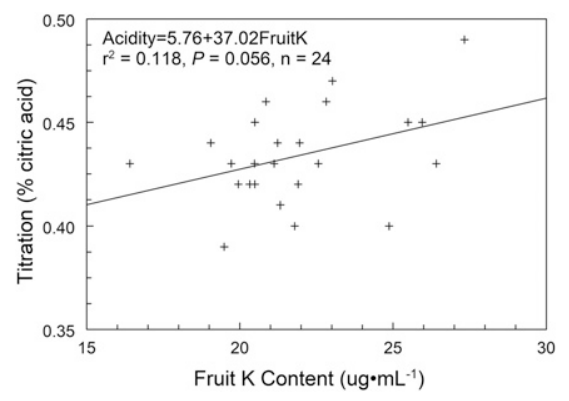

Fig. 2. Relationship between fruit potassium $(K)$ concentration and titratable acidity (\% citric acid) of pineapple $\left(1 \mu \mathrm{g} \cdot \mathrm{mL}^{-1}=1 \mathrm{ppm}\right)$.

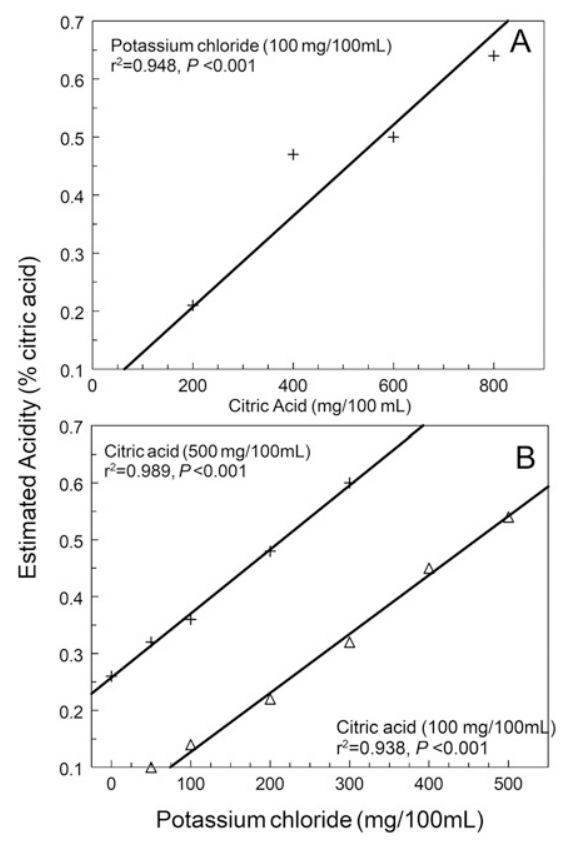

Fig. 3. The effect of increasing concentration of citric acid and digital acidity meter estimated acidity (A), and $(B)$ the acidity determined with the digital acidity meter with variable potassium chloride (KCL)

concentration $(0$ to $300 \mathrm{mg} / 100 \mathrm{~mL})$ and fixed citric acid content ( 100 and $500 \mathrm{mg} / 100 \mathrm{~mL}$ ). Each data point is the mean of three separate readings $(1 \mathrm{mg} / 100 \mathrm{~mL}=10 \mathrm{ppm})$.
The digital acidity meter's instruction manual (7109-E03) does recognize that calibration by an offset function is necessary. This adjustment requires comparing titration values with the instrument reading to offset -5.0 to +5.0 . However, this offset would not allow for slope difference in the relationship between titration and meter reading of the two clones used in this study (Fig. 1).

\section{Conclusions}

The digital acidity meter has the potential for use in commercial settings in the field before harvest and for quality control in the packing shed and during marketing. The meter has utility to measure pineapple acidity in a single clone with regular seasonal recalibration via titration. Though not evaluated, fruit from fields having difference in available soil potassium or different fertilization practices may need more frequent recalibration. This digital acidity meter being an indirect measure of acidity might not be suitable for use in a research setting, and its usefulness would depend on the purpose and accuracy of the results required.

\section{Literature cited}

Apelblat, A. and J. Barthel. 1991. Conductance studies on aqueous citric acid. $Z$. Naturforsch. A. 46:131-140.

Bartholomew, D.P. and R.E. Paull. 1986. Pineapple, p. 371-388. In: P. Monselise (ed.). CRC handbook of fruit set and development. CRC Press, Boca Raton, FL.

Bartolome, A.P., P. Ruperez, and C. Fuster. 1995. Pineapple fruit morphological characteristics, chemical composition and sensory analysis of Red Spanish and Smooth Cayenne cultivars. Food Chem. 53:75-79.

Chan, H.T., Jr., E. Chenchin, and P. Vonnahme. 1973. Nonvolatile acids in pineapple juice. J. Agr. Food Chem. 21:208-211.

Chen, H., Y. Chen, X. Ye, D. Liu, and J. Chen. 2019. Turbidity, antioxidant compounds, color, and dynamics of clarification of bayberry juice using various polysaccharide-based clarifying agents. J. Food Process. Preserv. 43:el3980.

Dorey, E., P. Fournier, M. Léchaudel, and P. Tixier. 2016. A statistical model to predict titratable acidity of pineapple during fruit developing period responding to climatic variables. Scientia Hort. 210:19-24.
Huan, C., X. An, M. Yu, L. Jiang, R. Ma, M. Tu, and Z. Yu. 2018. Effect of combined heat and 1-MCP treatment on the quality and antioxidant level of peach fruit during storage. Postharvest Biol. Technol. 145:193-202.

Li, D., L. Li, G. Xiao, J. Limwachiranon, Y. Xu, H. Lu, D. Yang, and Z. Luo. 2018. Effects of elevated $\mathrm{CO}_{2}$ on energy metabolism and $\gamma$-aminobutyric acid shunt pathway in postharvest strawberry fruit. Food Chem. 265:281-289.

Marchal, J., A. Pinon, and C. Teisson. 1981. Effects of the form of potassium fertilizer on pineapple quality in the Ivory Coast. Fruits 36:737-743.

Muharfiza, D.F. Al Riza, Y. Saito, K. Itakura, Y. Kohno, T. Suzuki, M. Kuramoto, and N. Kondo. 2017. Monitoring of fluorescence characteristics of Satsuma mandarin (Citrus unshiu Marc.) during the maturation period. Horticulturae 3:51.

Paull, R.E. and C.C. Chen. 2003. Postharvest physiology, handling, and storage of pineapple, p. 253-279. In: D.P. Bartholomew, R. Paull, and K.G. Rohrbach (eds.). The pineapple: Botany, production and uses. CABI Publishing, Wallingford, UK.

Py, C., J.J. Lacoeuilhe, and C. Teisson. 1987. The pineapple: Cultivation and uses. Maisonneuve, Paris. <https://evols. library.manoa.hawaii.edu/handle/ $10524 / 55419>$.

Saradhuldhat, P. and R.E. Paull. 2007. Pineapple organic acid metabolism and accumulation during fruit development. Scientia Hort. 112:297-303.

Schifferstein, H.N. and J.E. Frijters. 1990. Sensory integration in citric acid/ sucrose mixtures. Chem. Senses 15:87109.

Shiina, T., T. Ijiri, I. Matsuda, T. Sato, S. Kawano, and N. Ohoshiro. 1992. Determination of Brix value and acidity in pineapple fruits by near infrared spectroscopy. Acta Hort. 334:261-272.

Singleton, V.L. and W.A. Gortner. 1965. Chemical and physical development of the pineapple fruit II. Carbohydrate and acid constituents. J. Food Sci. 30:19-23.

Smith, L.G. 1988. Indices of physiological maturity and eating quality in Smooth Cayenne pineapples. 2. Indices of eating quality. Queensl. J. Agr. Anim. Sci 45:219-228.

Soares, A.G., L.C. Trugo, N. Botrel, and L.F.D. Souza. 2005. Reduction of internal browning of pineapple fruit (Ananas comusus L.) by preharvest soil application of potassium. Postharvest Biol. Technol. $35: 201-207$. 
Soler, A. 1992. Pineapple. CIRAD-IRFA, Paris, France.

Spironello, A., J.A. Quaggio, L.A.J. Teixeira, P.R. Furlani, and J.M.M. Sigrist. 2004. Pineapple yield and fruit quality effected by NPK fertilization in a tropical soil. Rev. Brasil. Fruticultura 26:155159.

Subedi, P.P., K.B. Walsh, and D.W. Hopkins. 2012. Assessment of titratable acidity in fruit using short wave near infrared spectroscopy. Part B: Intact fruit studies. J. Near Infrared Spectrosc. 20:459-463.
Taniguchi, G., G.M. Sanewski, D.P. Bartholomew, and R.E. Paull. 2008. Characteristics of the pineapple research institute of Hawaii hybrids 73-50 and 73-114. Pineapple News 15(8), 27-33. <https:// scholarspace.manoa.hawaii.edu/bitstream/ 10125/41083/PineNews\%2015.pdf>.

Tisseau, M.A. and R. Tisseau. 1971. Application de la potasse sur ananas, après différenciation de l'inflorescence (notes préliminaires). Fruits 26:823-829.

Teerachaichayut, S. and H.T. Ho. 2017. Non-destructive prediction of total soluble solids, titratable acidity and maturity index of limes by near infrared hyperspectral imaging. Postharvest Biol. Technol. 133:20-25.

Wolf, A.V. 1966. Aqueous solutions and body fluids. Their concentrative properties and conversion tables. Harper and Row, Hoeber Medical Division, NY.

Wu, Q., Y. Zhou, Z. Zhang, T. Li, Y. Jiang, H. Gao, and Z. Yun. 2020. Effect of blue light on primary metabolite and volatile compound profiling in the peel of red pitaya. Postharvest Biol. Technol. 160:111059. 